\title{
Long-Term Options for Land Use in the European Community
}

\author{
R. Rabbinge* \& H. C. Van Latesteijn \\ Scientific Council for Government Policy, \\ PO Box 20004, 2500 EA The Hague, The Netherlands
}

\begin{abstract}
Agriculture in the European Community is going through a phase of accelerating changes that calls for major decisions. The continued increase in production per unit of land area and per unit of livestock, due to improved production circumstances, better cultivation methods and external inputs, has led to significant increases in agricultural productivity. Abundant use of fertilizers and pesticides in some regions has created considerable negative environmental side effects, whereas in other regions, under-use of external inputs has created environmental problems of another nature, such as erosion. Increase in productivity per unit of area will continue during the coming decades, as the gap between potential and actual yields remains very big and the efficiency of use of external inputs is generally greater at high than at low production levels. However, the production surpluses in the EC create budgetary problems for the EC and a strong distortion of the world market for agricultural products. Decreasing prices of agricultural products create bankruptcy of farms in the rural structure and environment. The orientation of the Common Agriculture Policy and the broadening of the objectives related to the rural environment need a clear and explicit formulation of options and a study of the possibilities and ways to achieve them. The Netherlands Scientific Council for Government Policy initiated such a study and developed various options for rural policy in which the preferences for a number of objectives related to agriculture and rural development are made
\end{abstract}

* Second address for this author: Department of Theoretical Production Ecology, PO Box 430, 6700 AK Wageningen, The Netherlands.

195

Agricultural Systems 0308-521X/92/\$05.00 ㄷ 1992 Elsevier Science Publishers Ltd, England. Printed in Great Britain 
explicit, and their consequences for land use are shown. Land use is chosen as the central theme because through changes in land use all other changes can be linked to each other. A qualitative and quantitative land evaluation is used to demonstrate the upper bounds for agricultural and forestry production.

\section{INTRODUCTION}

Systems analysis and simulation have developed into widely used and very useful tools in agricultural research. Both have been used as integrative tools and contributed to the structuring of research, to setting research priorities and to bridging gaps between disciplines. The investigative possibilities of simulation models in agriculture have not been used widely although their potential is high when combined with land evaluation.

The synthesis of systems analysis and simulation is demonstrated in this paper with a study by the Netherlands Scientific Council for Government Policy on possible changes in land use in the European Community. This illustrates how biotechnical and socioeconomic studies and analyses can be brought together.

\section{Land use changes in Europe}

The cultivated area of Europe has fluctuated considerably under the influence of changes in food demand caused by demographic events. Periods of expansion and contraction are, however, not unique to Europe and have occurred in cultivated areas all over the world. In Europe, from $\mathrm{AD} 1000$ to $\mathrm{AD} 1400$ (Fig. 1), cultivated land expanded as a result of population growth. Then a period of contraction followed due to decrease in the European population caused by plague epidemics and other diseases. Moreover, in the same period, productivity had increased with the introduction of crop rotation systems, in which legumes played an important role. Consequently the decimated European population could be fed from a much smaller area than before.

The same phenomenon can be seen in the period from the end of the seventeenth century until the middle of the eighteenth century. In the intermediate period, agricultural area expanded in response to population increase. From the middle of the eighteenth century until the late 1950s, the agricultural area steadily expanded again. Then it came to a standstill in Europe. The idea that we may be facing a new period of contraction is therefore not exceptional and to some extent is supported by the characteristics of the present situation. 




Fig. 1. Periods of increase and decrease of agricultural area in Europe.

\section{The present situation}

The productivity of European Community (EC) agriculture, measured in $\mathrm{kg}$ of dry matter per unit of area, continues to rise thanks to ongoing advancements in agronomic knowledge and the build-in incentive to increase productivity. The use of variable inputs (nutrients, pesticides) per unit of output decreases when higher yields per hectare are realized. When growing conditions are improved by measures such as soil improvement, irrigation, seed bed preparation, fertilization, etc., the crop shows a much better response to variable inputs. Therefore, proper agronomical measures lead to a situation where the efficiency of resource use will rise. A detailed analysis of this resource use efficiency in agriculture is given by De Wit (1992).

The continuing rise in productivity can be seen in other parts of the world. In Fig. 2, the increase in yield per hectare for wheat is shown for both the UK and the USA. The discontinuity after World War II is due to innovations from various disciplines, better known as the first 'green revolution' (Rabbinge, 1986). The first 'green revolution' was followed by a second, 20 years later, in the late sixties and seventies, in many developing countries. Independent of political system or economic conditions, the rate of increase of productivity reached very high levels, and technological improvement was the major impetus for this change.

In the EC the continuing rise in productivity has led to a considerable change in the level of self-sufficiency for major food products. In less than 25 years the EC changed from being a net importer of agricultural products into a net exporter of food. This is illustrated in Table 1 for the major food products-cereals, wine, butter and milk. After selfsufficiency was reached, productivity growth continued to rise as a result of the Common Agricultural Policy (CAP) of the EC. The CAP has a 


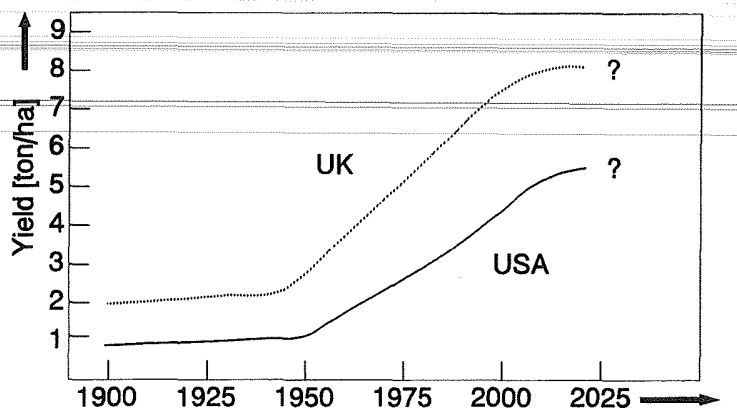

Fig. 2. Development of soil productivity for wheat in the UK and the USA.

system of guaranteed prices that creates a seemingly infinite demand. If supply is ample, the guaranteed prices impede a price signal to the producers to diminish their production. This has led to a situation of surplus production with major budgetary consequences. The system of guaranteed prices requires an ever increasing amount of money from the European tax payer to finance.

The budget problem has given rise to a call for a reform of the CAP. In recent years, the EC has tried to regulate production growth by introducing quota systems for sugar and milk and a system of co-responsibility levies for cereals. The guaranteed prices of cereals have especially led to problems with non-EC countries because they are not able to compete on the world market with the subsidized exports from the EC. The problems related to the liberalization of international trade in agricultural products form a substantial part of the current Uruguay-round of the GATT negotiations. In these negotiations the GATT is aiming at the reduction or elimination of all subsidies that have a distorting effect on the world market. For the EC this would lead to a significant cut in price subsidies.

TABLE 1

Self-Sufficiency in Cereals, Sugar, Butter and Meat in the EC Given as the Rate Between Domestic Production and Domestic Consumption, 1975 and 1989

\begin{tabular}{lll}
\hline & 1975 & 1989 \\
\hline Cereals & 0.94 & $1 \cdot 15$ \\
Sugar & 0.87 & 1.36 \\
Butter & 0.97 & 1.34 \\
Meat & 0.96 & 1.01 \\
\hline
\end{tabular}


The discussion on instruments and objectives in the EC concentrates on price subsidies. From the very start the CAP was dominated by guaranteed prices, leading to a system of import levies and export subsidies. Instruments to promote agricultural production through structural changes such as land reclamation were added much later. Such structural policies are present in many countries at the national level, in The Netherlands for example. Governments were willing to support this and the development of agricultural research, education and extension. The combination of public management and private entrepreneurship has helped the development of the agricultural sector considerably. In spite of the surplus production there is no tendency to reduce the structural improvement programs in many countries. On the contrary, more and more EC-subsidies are used for structural strengthening of the production circumstances which will stimulate a further rise in productivity.

At the same time attention has grown for goals other than agricultural production. It is recognized that environment, employment and farmers' income are tightly linked to developments in agriculture, and thus to agricultural policy. The deterioration of landscape and the natural environment has resulted in much criticism of agriculture. Another important point is the considerable overuse of pesticides and plant nutrients due to their low prices, which has created immense environmental problems in some parts of the $\mathrm{EC}$. The continuing rise in productivity means that food security within the Community can be guaranteed with only a relatively small number of farmers in a relatively small area. This in turn implies that much space and a large portion of the work force may be put to other uses, such as nature conservation and recreation.

\section{Limitations to growth in productivity}

The study by the Netherlands Scientific Council for Government Policy aimed at exploring the options for future land use in the EC by defining the limitations to growth in productivity. In the end those limitations will define the possibilities of agriculture in the Community. In the study three types of limitations were distinguished:

1. Technical limitations: there is a well defined yield maximum for each crop, given the properties of the crop, the properties of the soil and the actual climatic conditions. This determines how much useful product can be produced when plants grow under optimal conditions. 
2. Demand limitations: now that population growth in the EC has come to a stand-still, increases in consumption may occur but will be very limited. Moreover, export potential of food products appears to be limited. The same holds true for the potential of non-food use of agricultural produce (agrification). Although there is an enormous area available, the value added per unit area is very low for bulk production of energy and fiber crops. Farmers will only be able to generate a fair income in the distant future through these types of production on energy farms of considerable size.

3. Limitations that stem from policy goals: objectives in the field of nature conservation, recreation and the like will set limits to the location and nature of agricultural production. Because policy goals are subjective by nature these limitations will be relatively controversial.

The study reported in this paper was focused on the effects of policy choices in relation to technically possible growth in productivity, i.e. the study assessed the consequences of future land use in the EC due to limitations that stem from policy goals.

\section{METHODOLOGY}

A computer model, GOAL (General Optimal Allocation of Land use), was developed which calculates optimal land use in the Community of the twelve member-states (the territory of the former GDR was not included). The optimal allocation of land use is calculated by considering the possibilities of alternative types of land-use to produce an exogenous given demand, with a set of constraints. This is illustrated in Fig. 3.

Inputs to the model are technical information on various aspects of agricultural production and policy views. The technical information is divided into information on the production potentials in various parts of Europe, information on production techniques and information on the demand for food products.

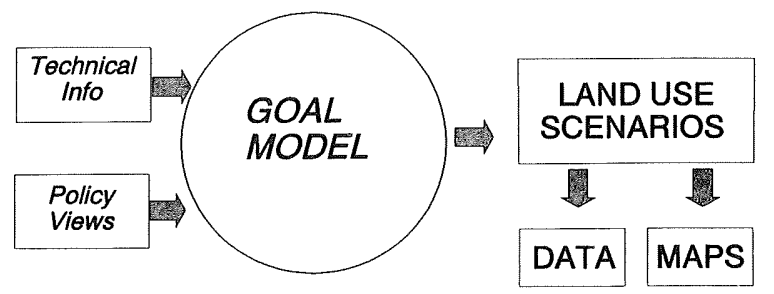

Fig. 3. Inputs and outputs of the GOAL model. 


\section{Technical information on production potentials}

The production potentials were determined using a detailed qualitative and quantitative land evaluation with a combination of Geographical Information System (GIS) and crop growth simulation. This was done by using a soil map (1:1000 000) of the European Community. Homogeneous units of soil and climate were distinguished by screening with a set of criteria to determine what land use is possible. The most demanding form of land-use (arable farming) was found to vary between 15\% (in Greece) and $80 \%$ (in Denmark) of total area. The attainable yield per homogeneous unit was determined by coupling a simulation model of crop growth to the GIS.

\section{Technical information on production techniques}

This concerns a detailed description of techniques that enable the production of the crop growth potentials determined above. The techniques are variable inputs such as labour hours, fertilizers, pesticides and machinery. These techniques are defined such that they are in agreement with the production potentials. In situations where rainfed production is limited, use of inputs such as fertilizers and pesticides are tailored according to needs. Various production techniques are distinguished (Van Latesteijn, 1992).

\section{Technical information on the demand for food products}

Two assumed demands for internal food production in the EC are derived (i.e. a situation of free market-free trade and a situation of autarchy). Also, two different diets, dependent on meat and dairy consumption, are distinguished.

Next to the 'objective' technical information, policy views are used that indicate a desired (thus, subjective) priority between different goals and the levels to which these goals should be fulfilled. Four policy views are distinguished, as follows:

1. free market and free trade: economic productivity and minimization of the costs are the prevailing characteristics;

2. regional development: maintaining employment in agriculture and the promotion of income in the agricultural sector are the dominant aims;

3. nature development and landscape conservation: minimization of the change in land use in order to conserve the landscape and develop natural conditions; 
4. environmental protection: minimization of the negative side effects of agriculture and therefore minimization of pesticide use and artificial fertilizers are dominating aims.

To make these views operational, a set of explicit goals is formulated for use in the model. The relative priority for each of these goals is different for each of the policy views. The goals used in GOAL are given in Table 2. Four types of goals are distinguished:

1. agricultural goals: such as maximization of soil productivity and minimization of the costs for agricultural production;

2. socio-economic goals: such as maximization of the total number of people employed in agriculture, or minimization of the regional decrease in employment in agriculture;

3. environmental goals: such as minimization of inputs of nutrients and pesticides per unit of area or per unit of product;

4. nature and landscape goals: such as maximization of land use for nature conservation and minimization of change in land use.

The last category turned out to be very difficult to implement in GOAL. Objectives related to nature and landscape are site- or location-specific, making it difficult to define a general rule that models these objectives. Therefore ex post analyses were performed to provide information on the fulfillment of these goals.

Policy views, made operational through various goals and technical information, are introduced in the model and used to derive scenarios for land-use. The land-use scenarios are formulated at the level of political administrative units (NUTS-1) because it is impossible and unrealistic to run GOAL for all 22000 units distinguished in the land evaluation study. Moreover, decisions and policy implementation take place at these higher levels of aggregation. The NUTS-1 level (the EC divided into 64

TABLE 2

Objectives Incorporated in the GOAL Model

\begin{tabular}{lll}
\hline Class of objective & & \multicolumn{1}{c}{ Objective } \\
\hline Agricultural & 1 & maximize soil productivity \\
Socioeconomic & 2 & minimize costs of agricultural production \\
& 3 & maximize total employment in agriculture \\
Environmental & 5 & minimize regional decrease in employment in agriculture \\
& 6 & minimize input of nutrients per unit of acreage \\
& 7 & minimize input of nutrients per unit of product \\
& 8 & minimize input of pesticides per unit of acreage \\
& &
\end{tabular}


regions) was an arbitrary choice, compromising the detail dictated by land evaluation and physical production circumstances and the more general level dictated by policy making. Policy-makers can now see how their priorities will affect land use at the level of NUTS-1 regions and how these effects are distributed over the EC.

The scenarios show possible options under favorable circumstances for agricultural production. We assumed that farmers use the best technical means and that farming activities are located where soil and climate conditions are suitable for a well defined cropping system. The scenarios therefore give an indication of the 'ceiling' for growth in the productivity of land-based agriculture.

\section{RESULTS}

The qualitative and quantitative land evaluation of the EC showed where crops could be grown and what the attainable crop-yields are at a given location. Two situations were distinguished: a maximum yield, using only the available water (rainfed agriculture) which we call 'water-limited yield' and a maximum yield when irrigation or drainage removes water limitation (we call this 'potential yield', because it shows the absolute maxima). Taking wheat as an example Fig. 4 illustrates the water-limited yield of wheat for the NUTS-1 regions in the EC. The different shadings represent the maximum attainable yield per ha within each region under optimal conditions, but with the water supply limited to rainfall. The

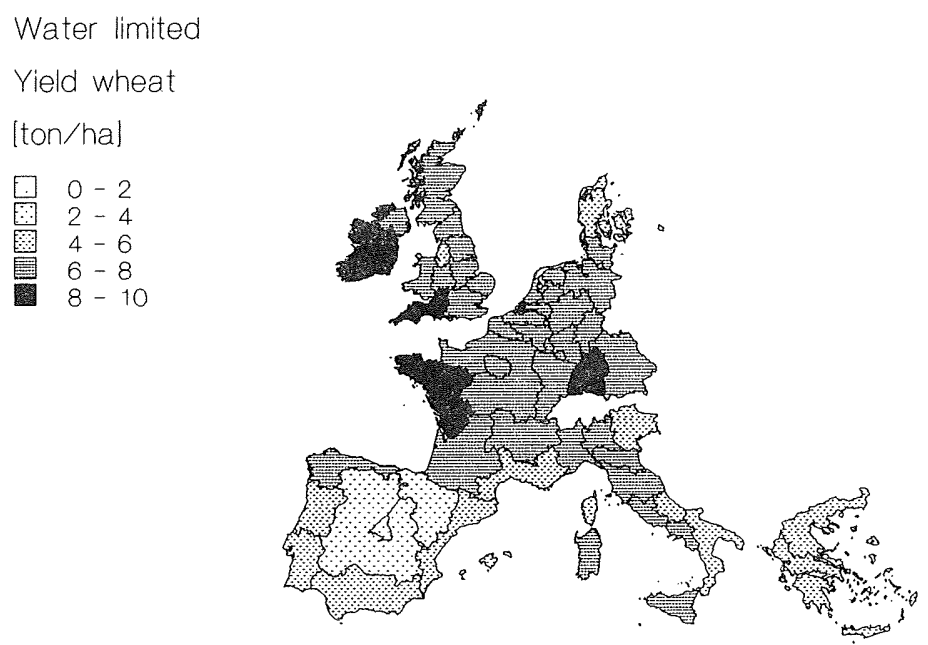

Fig. 4. Water-limited yield for wheat in the EC based on calculations derived with a crop growth simulation model. 
given results are averages; parts of the regions indicated are not suitable for wheat farming. The aggregation from detailed land evaluation studies to the NUTS-1 level was done by using weighted averages (Van Lanen, 1990).

Figure 5 shows the results if the water limitation is removed. The assumption is made here that in some regions extensive irrigation schemes are introduced. High yields can then be obtained almost anywhere because most of the physical comparative advantages are eliminated. However, in many cases this involves high costs for land reclamation, and indicates an extreme situation, showing what is technically possible. No account is taken of the possibilities or impossibilities of irrigation in real life. However, in the GOAL model, irrigation costs and the availability of water are incorporated to prevent such unfeasible outcomes. The quantitative land evaluation was carried out for cereals, grassland, oil seed crops, protein crops and root crops.

The qualitative land evaluation was carried out for traditional agricultural products and forestry. The resulting possibilities show that areas favorable to forestry coincide with the higher yielding arable farmlands, even in the case of low demanding tree species.

The results for land evaluation and methods of production are striking. The various production techniques distinguished make clear that present practices in agriculture in many areas in North Western Europe have led to a significant overuse of pesticides and nutrients. The possibilities of decreasing the level of inputs without losing productivity and increasing the efficiency of resources are therefore high.

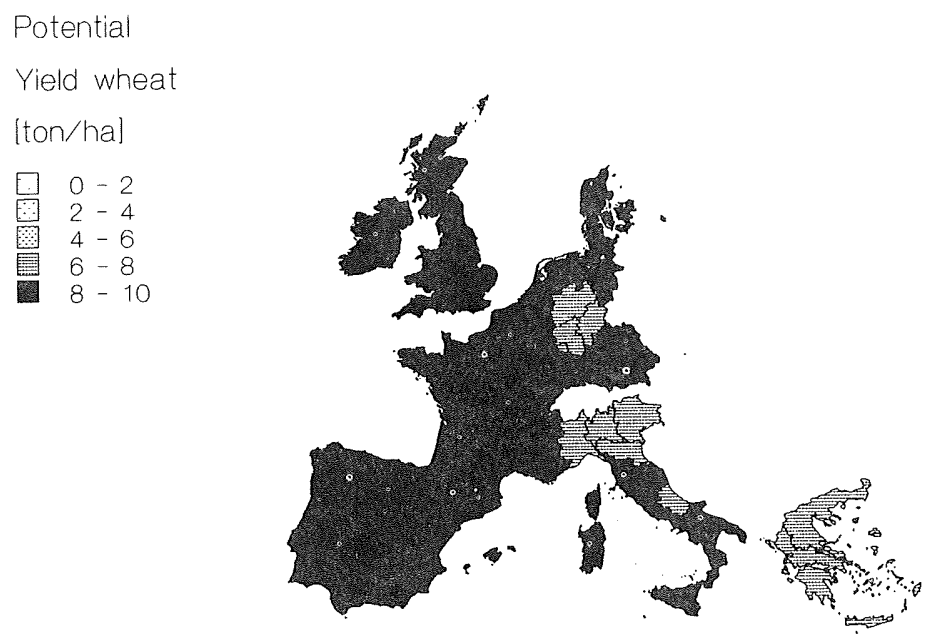

Fig. 5. The potential yield for wheat in the EC based on calculations derived with a crop growth simulation model. 
Another result of the study is a map that shows the preferred locations for nature conservation and development. The criteria used to determine where nature conservation or development should be promoted include, amongst others, species diversity and protection of rare ecosystems that are necessary for the survival of some species. The resulting 'European Ecological Network' is based on information gathered from all member states.

To quantify the demand for food, a study was carried out that evaluated the results of many econometric general equilibrium models for world trade in agricultural products. The outcomes of these models were summarized in terms of probable demand for various product groups in a situation of free trade-free market. In the case of autarchy, the present maximum demand is used for the present diet and a changed diet. The technical information described above was collected by various research groups. All this information was brought together in the GOAL model, where technical information and policy views meet, resulting in various scenarios.

\section{CALCULATION OF SCENARIOS}

GOAL was used to calculate scenarios on the basis of alternative policy views. Each policy view results in a different scenario, but there are also general results that may be of interest to policy-makers.

A first result shows that all options imply a radically diminished use of land for agricultural purposes. At present in the EC, about $130 \times 10^{6}$ ha are used as farmland. All scenarios show a spectacular decline to roughly $30-60 \times 10^{6}$ ha in about two to three decades. Even if labour is maximized within agriculture and extensive land-use-oriented production techniques are accepted, not more than $90 \times 10^{6}$ ha will be needed for production. This should be considered as a technical maximum.

There are three reasons for this considerable difference between the scenario results and the present situation:

1. The production achieved in the scenarios is, in many regions, much higher than the actual values. Due to the use of the best land and a relatively high level of production on that land, the area in use for this highly efficient agriculture is very small;

2. The cropping systems used in the scenarios are highly technically efficient, so that limitations or reductions due to sub-optimal production techniques or inadequate use of input are eliminated; and

3. Production takes place mainly in the best locations, so that marginal areas where only relatively low production is achieved, have only a limited effect on the average. 
A second result from the scenarios is that, by using the best technical means under optimal conditions, only $1.5-3 \times 10^{6}$ man years are needed for total agricultural production. In 1987, about $7 \times 10^{6}$ man years were involved in primary production. The considerable decline in man years needed in land-based agriculture is caused by the elimination of hidden unemployment and the efficient use of labour. An analysis of hidden unemployment in agriculture in the EC showed that in 1987 there was already an enormous surplus of labour in agriculture.

A third interesting feature of all scenarios is the dramatic decrease in the use of pesticides. Under optimal conditions only $40-80 \times 10^{6} \mathrm{~kg}$ active ingredient is needed throughout the EC. In 1987, more than $400 \times$ $10^{6} \mathrm{~kg}$ is used.

A fourth result concerns the input of nutrients. In $1987,8.5 \times 10^{6} \mathrm{t}$
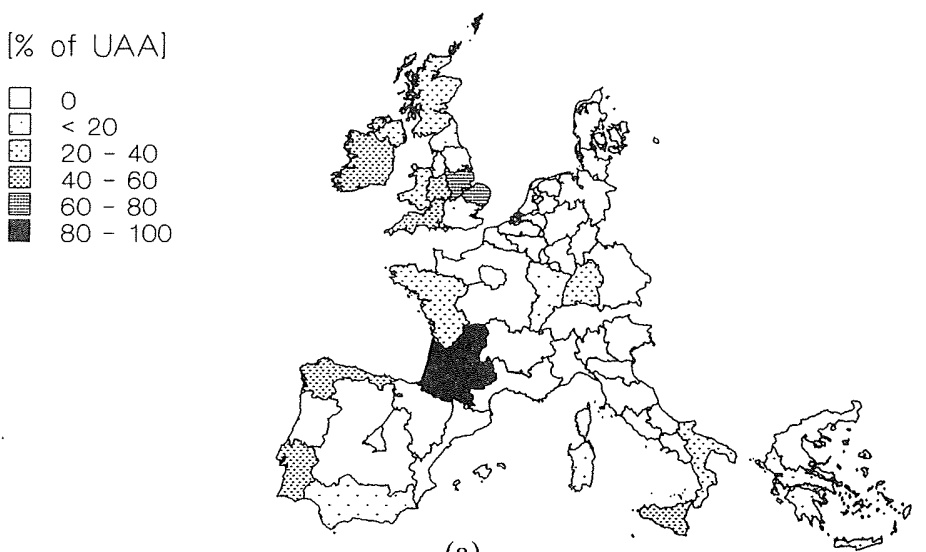

(a)
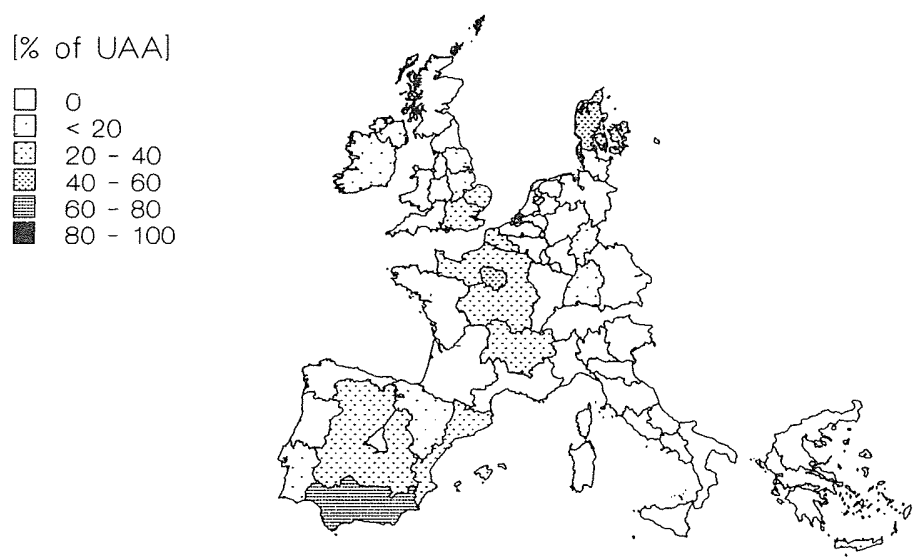

(b)

Fig. 6. The allocation of cereal production in Scenarios (a) and (b) (see text). (The shading indicates the percentage of the suitable area per region that is actually used.) 
nitrogen fertilizer were used. In model calculations, the minimum amount is about $2 \times 10^{6} \mathrm{t}$ fertilizer. The limited amount of land where high production levels are achieved does require a less than proportional use of inputs. Therefore pesticide use efficiency and fertilizer use efficiency are very high. This also holds for energy and labour use efficiency (De Wit et al., 1987).

Maps derived with GOAL further demonstrate the location of land use and production techniques given different policy views. Two alternative policy views are given here as examples. The first policy view concerns free market-free trade. In Scenario (a), costs of production should be as low as possible. The second policy view, Scenario (b), concerns stimulation of regional employment in a situation of autarchy in the EC; regional employment is maximized in this scenario.
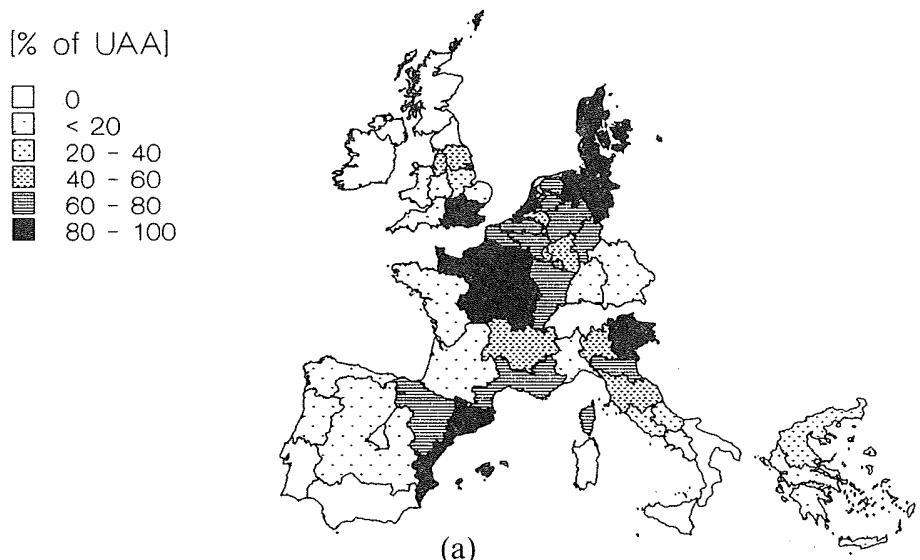

(a)
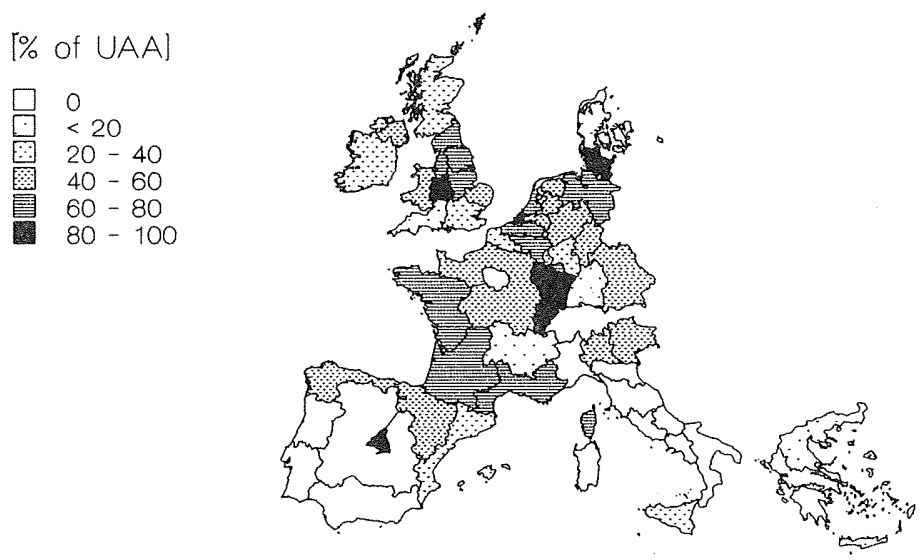

(b)

Fig. 7. The allocation of grass production in Scenarios (a) and (b) (see text). (The shading indicates the percentage of suitable area per region that is actually used in the scenario.) 
Figure 6 shows the location of cereal production according to these alternative policy views. On the map the fraction of land used for cereal growing is given. The volume of production -is equal in both scenarios, but the locations differ. In Scenario (b) the production is spread wider across the regions in order to fulfil the goal of regional employment. In Scenario (a) only the most efficient regions are used for production.

In Fig. 7, the locations of grassland are shown in the two scenarios. These maps are to be viewed in connection with the previous two. The allocation in Scenario (a) clearly shows that grasslands in some areas near the Mediterranean are optimal in terms of minimizing production costs, and may be an effect of the longer growing season in Southern regions.

These examples of the two scenarios show that not only can information on important macro policy indicators be provided by GOAL, but also that an optimal allocation of land-use may be derived.

\section{CONCLUSIONS}

In this paper, a combination of various techniques and disciplines has been presented. GIS and crop growth simulation studies were used for qualitative and quantitative land evaluation. Detailed agronomical analysis and detailed crop growth studies have led to the definition of production techniques that indicate the relationship between various inputs and outputs. Analysis of econometric studies on world trade markets of agricultural products helped to formulate the demand for food produced within the EC. Detailed environmental studies helped to derive an ecological structure for the EC.

The combination of all this technical information with policy views has led to the assessment of options for future land-use in the EC. This range of options may help in strategic policy planning and may set ultimate aims for mitigating policy instruments.

From the results of the study it may be concluded that major changes in land-use are inevitable in all policy options. All scenarios point to a dramatic decrease in farmland. About one third of the present area under cultivation will be sufficient once productivity in the EC reaches the optimum. It should be noted, however, that the scenarios explore possibilities, and do not make predictions.

The differences between the scenarios indicate that there is room for policy change, but the possibilities of mitigating effects are severely limited. This is illustrated in Fig. 8; this graph shows that present land use of $130 \times 10^{6}$ ha will eventually come down to the range that was 


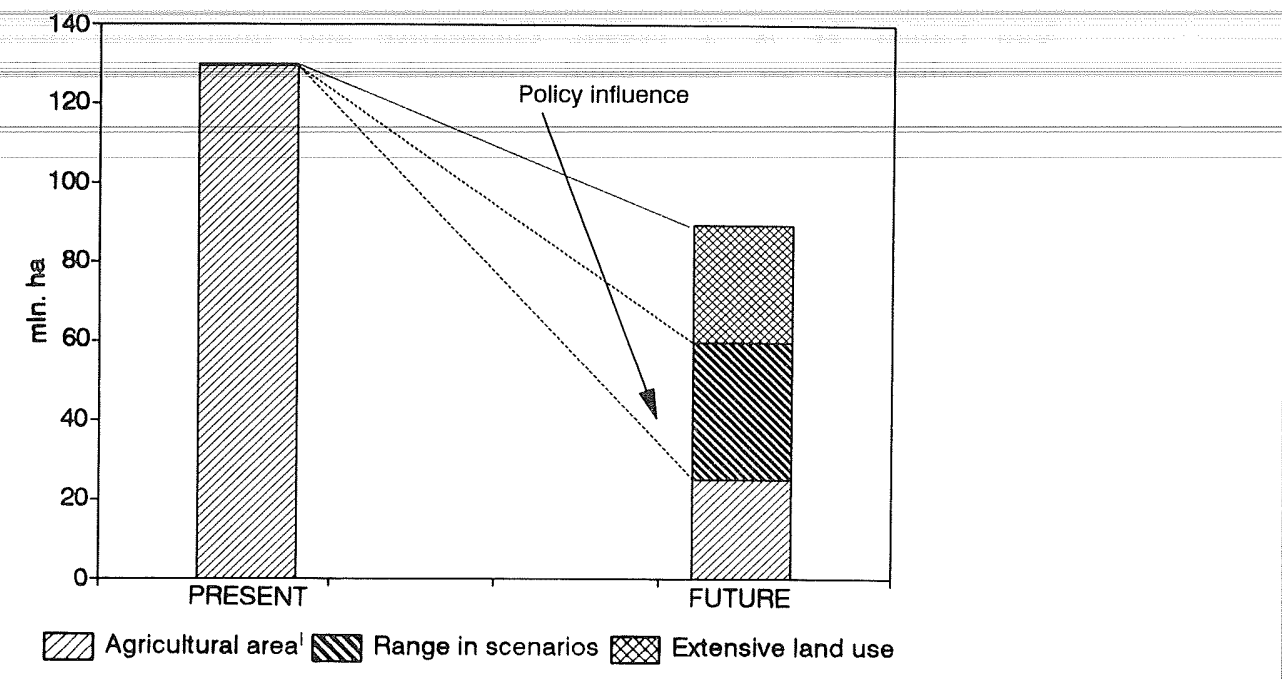

Fig. 8. The relative influence of policy objectives on the calculated future utilized agricultural area.

mentioned, although these figures are extremes. Technical development will bring about a maximum decrease of $100 \times 10^{6}$ ha if the best technical means are used for agricultural production. Through policy intervention, it may be possible to opt for either the lowest area of $30 \times$ $10^{6}$ ha or the highest area of $60 \times 10^{6}$ ha. However, acceptance of extensive types of agriculture may increase the area with $50 \times 10^{6}$ ha. So policy will have an effect, but, compared to the decrease brought about by technical improvements, this effect will be limited.

Policy goals, however, can have a major influence on the distribution of agricultural production locations in the member states, as shown by the maps generated in the study. The present study has demonstrated that the scope for strategic decisions is limited, and any reform of the CAP should considered these limitations.

\section{REFERENCES}

De Wit, C. T. (1992). Resource use efficiency in agriculture. Agric. Systems, 40(1-3), 125-51 (this issue).

De Wit, C. T., Huisman, H. \& Rabbinge, R. (1987). Agriculture and its environment: Are there other ways? Agric. Systems, 23, 211-36.

Rabbinge, R. (1986). The bridge function of crop ecology. Netherlands J. Agric. Sci., 34, 239-51. 
Van Lanen, H. A. J. (1990). Qualitative and quantitative physical land evaluation: an operational approach. Thesis: Landbouw Universiteit, Wageningen, The Netherlands. $195 \mathrm{pp}$.

Van Latesteijn, H. C. (1992). A methodological framework to explore long-term options for land use. In Systems Approaches for Agricultural Development, eds F. W. T. Penning de Vries, P. S. Teng \& K. Metselaar. Kluwer Publishers, The Netherlands (in press). 